or more parts each of which is grown into a complete seedling. By repeating the process a large population of genetically identical plants is produced. And if the starting meristem came from a plant of high oil yield, the population derived from it by meristem culture should also be high yielders.

Twyford has already shipped clonal populations of jojoba to Arizona for field trials, but admits that the project is still in its infancy, not least because there is a fiveyear time lag before a plant bears its first crop of nuts.

Even if everything goes according to plan and jojoba oil becomes available at a low price, it is by no means certain that there will be a market for it. According to Highgate and Joab, a major sperm oil refiner now concerned with the development of substitutes, had jojoba oil been available when sperm oil was withdrawn from Britain and the United States, its market would have been assured because it could have replaced sperm whale oil in nearly all of its diverse uses. But industry has since become accustomed to using different oils for different processes and today's market will simply judge whether jojoba oil is better than any of these oils for a particular application. The most likely future for jojoba oil now lies in small specialized fields where no other reasonable alternative exists. Melanie Kee

\section{Cancer prize}

\section{Washington}

The Hammer Prize Foundation has awarded its first $\$ \mathbf{1 0 0 , 0 0 0}$ prize for cancer research to Dr Ronald Levy of Stanford University and George Stevenson of the University of Southampton (in Britain). They were cited for their work on monoclonal antibodies in the treatment of B-cell leukaemia and lymphoma.

The prize, which will be awarded annually for ten years, was established by Armand Hammer, the chairman of Occidental Petroleum. Hammer has offered an additional \$1 million for a "cure" for cancer similar to the cure for polio achieved by Dr Jonas Salk. The annual prizes are for the scientists who have made the "greatest contribution towards a cure".

The prize has stirred a certain amount of controversy, both for its origins and for its terms. Some researchers question its focus on treatment, rather than basic research, saying that such an emphasis encourages "premature jabs". And there has been grumbling, too, about Hammer's ties with Occidental, the parent company of Hooker Chemical of Love Canal fame. Hammer's appointment to head the President's Cancer Panel - previously a panel of medical experts - had earlier provoked similar criticisms. Stephen Budiansky

Chemical toxins

\title{
USA and UN disagree
}

Washington

The issue of the use of Soviet toxic weapons in South-East Asia remains disputed. While the US State Department continues its campaign to convince sceptics that Soviet toxin weapons have been used in Afghanistan and South-East Asia, a long-awaited report by a United Nations (UN) group of experts has provided only inconclusive findings.

The most dramatic pieces of evidence now produced by the State Department are two Soviet gas masks obtained in "clandestine operations" in Afghanistan. According to the US Army Chemical Systems Laboratory, which analysed the masks, traces of several trichothecene mycotoxins were found on the surfaces and hose connections of the masks. These fungal toxins are said by the State Department to have been used extensively in Laos and in Kampuchea, where "yellow rain", attacks were first reported.

The State Department has also released analyses of blood, urine and tissue samples from 33 alleged victims of toxin attacks; trichothecenes were found in 16 of the subjects. "The finding of T-2 toxin and HT-2 toxin (a metabolite of T-2 toxin in animals) in the blood, urine and tissue of victims of these attacks provides unequivocal evidence of their use as weapons", the State Department concludes.

But in its report to the UN SecretaryGeneral, the group paints a far more complex picture. Most striking is the utter confusion that the group found in refugees' reports of attacks and claimed illnesses. Two Hmong refugees who said they developed a rash after a chemical attack two weeks earlier were found on examination to have three-month-old fungal infections. Some others who attributed their illnesses to chemical weapons were found to have malaria, or in one case, a gastric ulcer. The group also found discrepancies in reports of numbers of fatalities, the colour of the agent said to have been sprayed and the timing and seriousness of the effects. The group's work had, however, been complicated by the denial of access to Laos and Kampuchea and was limited to interviewing and examining refugees who had crossed into Thailand long after the alleged attacks took place.

The most the UN group was willing to concede was that there is "circumstantial evidence" for the use of "some toxic material" 'in the areas of Laos inhabited by the Hmong. The group found stories of chemical weapons use in Afghanistan less believable, attributing reports there to incendiary weapons (which would give off irritating smoke as a by-product of combustion) and to a harassing agent such as adamsite. And reports of rapid decomposition of the bodies of chemical attack victims - which have been given prominent attention by the State Department - were "difficult to reconcile with known facts about the effects of chemical warfare agents or other chemical compounds".

Chemical analyses performed for the UN study were likewise inconclusive. Two of the laboratories that analysed blood and leaf samples from Thailand were unable to detect any trichothecenes - even in a control sample spiked with the compounds. A third laboratory reported trichothecenes in all samples submitted, including a blank control.

Furthermore, the possibility of crosscontamination of samples is always present; in addition, the identification of trichothecenes is to some degree a function of the analyst's experience and judgement.

The State Department has tried to avoid argument about its analyses by sending samples to Dr Chester Mirocha, a leading authority on the analysis of trichothecenes. Mirocha's technique is to react samples with trifluoroacetic acid; this produces volatile derivatives of trichothecenes that may then be separated by gas chromatography (GC) and analysed by mass spectrometry. A combination of the GC retention time and the mass-spectrometer peaks can provide "certain" identification, Mirocha says, with a detection limit of less than one part in $10^{\circ}$. The blood and tissue samples that he analysed contained trichothecenes in the range $10-100$ parts in $10^{9}$.

Mirocha points out that even among workers in laboratories with a great deal of experience, quantitative results of trichothecene analyses can vary by as much as 3060 per cent; in experienced laboratories the variations would not surprisingly be much greater, he says. "Some people have come into this entirely cold. Just because they're chemists doesn't mean they can automatically analyse for trichothecenes", says Mirocha. The UN group used laboratories at the Tokyo University of Science (run by Dr Y. Ueno, who, along with Mirocha, is considered to be one of the world's experts), the University of Veterinary Medicine in Vienna, and the Technical Research Centre in Espoo, Finland (see Nature 16 December, p.569).

But reliable as Mirocha's analyses may be, several independent experts question seriously what exactly he has been analysing. The gas masks, for example, were first analysed at the Army's laboratory; Mirocha was sent only a chloroform extract and asked to confirm the presence of T-2. Mirocha says he was also sent a piece of rubber or plastic on which he was unable to detect any of the toxins.

The State Department refuses to say how the masks were obtained, and independent verification of their origin and handling is 